\title{
ICESat laser altimetry over small mountain glaciers
}

\author{
Désirée Treichler and Andreas Kääb \\ Institute of Geosciences, University of Oslo, P.O. Box 1047, 0316 Oslo, Norway \\ Correspondence to: Désirée Treichler (desiree.treichler@geo.uio.no) \\ Received: 28 December 2015 - Published in The Cryosphere Discuss.: 26 January 2016 \\ Revised: 6 July 2016 - Accepted: 28 July 2016 - Published: 16 September 2016
}

\begin{abstract}
Using sparsely glaciated southern Norway as a case study, we assess the potential and limitations of ICESat laser altimetry for analysing regional glacier elevation change in rough mountain terrain. Differences between ICESat GLAS elevations and reference elevation data are plotted over time to derive a glacier surface elevation trend for the ICESat acquisition period 2003-2008. We find spatially varying biases between ICESat and three tested digital elevation models (DEMs): the Norwegian national DEM, SRTM DEM, and a high-resolution lidar DEM. For regional glacier elevation change, the spatial inconsistency of reference DEMs - a result of spatio-temporal merging - has the potential to significantly affect or dilute trends. Elevation uncertainties of all three tested DEMs exceed ICESat elevation uncertainty by an order of magnitude, and are thus limiting the accuracy of the method, rather than ICESat uncertainty. ICESat matches glacier size distribution of the study area well and measures small ice patches not commonly monitored in situ. The sample is large enough for spatial and thematic subsetting. Vertical offsets to ICESat elevations vary for different glaciers in southern Norway due to spatially inconsistent reference DEM age. We introduce a per-glacier correction that removes these spatially varying offsets, and considerably increases trend significance. Only after application of this correction do individual campaigns fit observed in situ glacier mass balance. Our correction also has the potential to improve glacier trend significance for other causes of spatially varying vertical offsets, for instance due to radar penetration into ice and snow for the SRTM DEM or as a consequence of mosaicking and merging that is common for national or global DEMs. After correction of reference elevation bias, we find that ICESat provides a robust and realistic estimate of a moderately negative glacier mass balance of around $-0.36 \pm 0.07 \mathrm{~m}$ ice per year. This regional esti-
\end{abstract}

mate agrees well with the heterogeneous but overall negative in situ glacier mass balance observed in the area.

\section{Introduction}

The role of mountain glaciers and snow as sources for drinking water, irrigation, and hydropower is getting increasing attention, not least due to the significant population increase and economic development in a number of mountain regions and surrounding lowlands (Jansson et al., 2003; Viviroli et al., 2007). Retreat of mountain glaciers is also a major cause of eustatic sea level rise (Gardner et al., 2013), but the response of some large glacierized systems to climatic changes is still poorly quantified, especially in regions with large climatic variability. The glacier regions least represented in long-term in situ glacier monitoring programmes are those with the largest ice volumes (Zemp et al., 2015), which are less inhabited and difficult to access and, therefore, are not well studied. Regional estimates of ice loss recently gained importance, not least for assessing the current and future contribution of water stored in land ice masses to sea level rise (Gardner et al., 2013; Jacob et al., 2012; Marzeion et al., 2012; Radić et al., 2014; Radić and Hock, 2011) and for quantifying current run-off contribution from glacier imbalance (Kääb et al., 2015) or changes in the upstream cryosphere (e.g. Bliss et al., 2014; Immerzeel et al., 2010). Remotely sensed data are of special value in remote mountain regions where measurements such as in situ mass balance measurements are sparse or lacking completely.

Elevation data from the Geoscience Laser Altimeter System (GLAS) on board the NASA Ice, Clouds, and Land Elevation Satellite (ICESat) provides what is likely the most consistent global elevation measurement currently available (Nuth and Kääb, 2011). The use of this data to derive thick- 
ness changes of Arctic ice caps is well established (Nuth et al., 2010; Moholdt et al., 2010; Bolch et al., 2013; Nilsson et al., 2015; Slobbe et al., 2008). Kääb et al. (2012) have shown that, when combined with reference heights from a digital elevation model (DEM), ICESat data can successfully be used to derive regional-scale glacier mass balance even in rough topographies such as the Himalayas. Subsequently, ICESat elevation measurements combined with the Shuttle Radar Topography Mission (SRTM) DEM were used to estimate sea level rise contributions from mountain glaciers globally (Gardner et al., 2013), regionally in high-mountain Asia (Neckel et al., 2014; Kääb et al., 2015) and even for local glacier mass balance studies in the Kunlun Shan (Ke et al., 2015) and the Alps (Kropáček et al., 2014).

The increased public interest in glacier retreat, not least due to its effects on water resources stored in mountain glaciers, requires that the performance of ICESat over such terrain is carefully evaluated and associated error sources are well characterized. This is especially important given that using ICESat data over mountain topography is at (or even exceeds) the limits of what the mission was designed for. As a case study for this purpose we chose the mountains of southern Norway. With its comparably small and sparse glaciers, situated within a varied topographic setting of both steep and gentle mountains, we consider the region as a representative case for the limits of applicability of ICESat data for analysing changes of mountain glaciers. In contrast to large, remote areas like high-mountain Asia, the climatic framework and glacier responses are relatively well known and measured in southern Norway, and accurate, up-to-date glacier masks and a high-resolution reference DEM are available.

Specifically, we aim to address the following questions in our study.

- What prerequisites and conditions need to be fulfilled to make ICESat-derived elevation changes over a certain area a valid method to assess glacier volume changes?

- Is the ICESat track density high enough for the sparse glacier cover in the study region, and are the point samples along ICESat profiles representative of the whole glacier population in southern Norway?

- Can a realistic elevation trend be retrieved for the years 2003-2009 (glacier volume loss), and is it possible to detect climate-related patterns, namely the spatial transition from maritime towards more continental glaciers with increasing distance to the coast?

- What is the minimum region size with respect to glacier density for ICESat GLAS data to ensure statistically significant results? Are realistic annual glacier thickness changes visible over a sufficiently sampled single glacier?

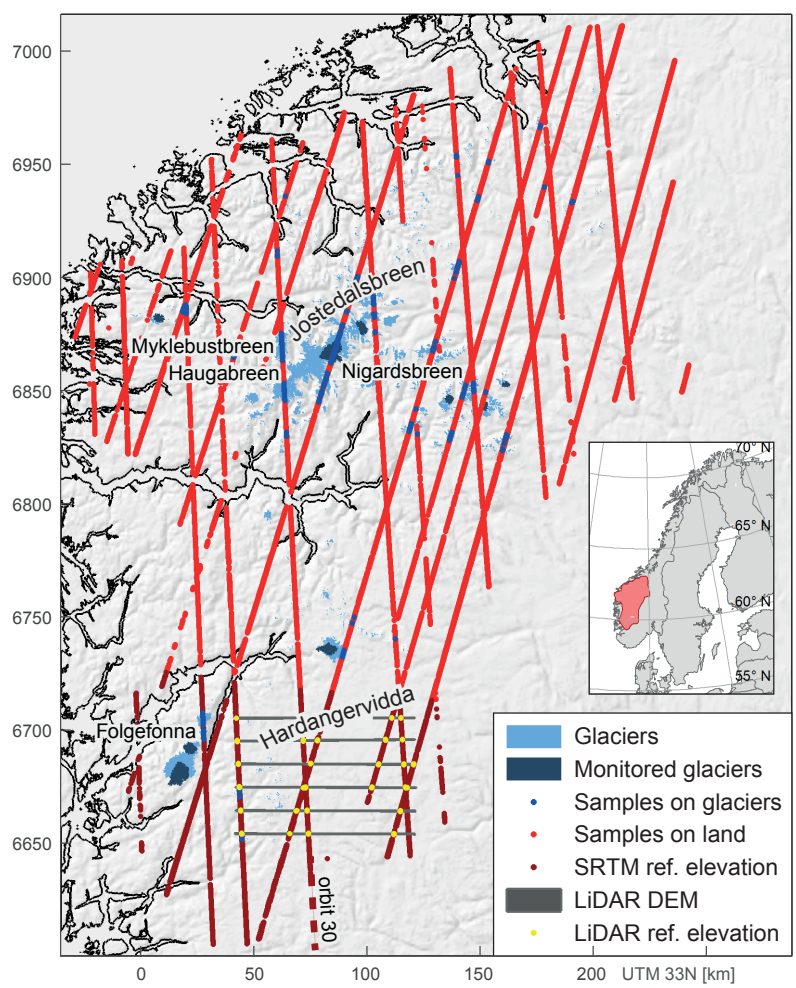

Figure 1. ICESat samples over glaciers and stable ground (land) in southern Norway. Only used footprints are displayed (no footprints on clouds or water). Glaciers with ongoing monitoring by NVE are emphasized.

- How do the findings compare to observed glaciological and geodetic glacier mass measurements?

- How does the reference DEM influence the quality of the results, and how can the footprint reference elevation best be modelled?

\section{Study site and data}

\subsection{Southern Norway}

The study area referred to here as southern Norway extends over an area of $100000 \mathrm{~km}^{2}$ at $59-63^{\circ}$ latitude. It comprises all areas of the Scandinavian Mountains south of Trondheim that are within a $20-\mathrm{km}$ buffer around the glaciers (Fig. 1). While very steep, especially at fjord flanks, the study area consists of both rounded and rough mountains but also includes high-elevation plateaus such as Hardangervidda. The climate of the study area is governed by a west-east gradient from a maritime climate at the coast with high precipitation amounts to dryer conditions further east in the rain shadow of the Scandinavian Mountains (Melvold and Skaugen, 2013). This is also reflected in measured glacier net balance magnitudes (Kjøllmoen et al., 2011). The Norwe- 
gian glacier area has recently been mapped by the Norwegian Water Resources and Energy Directorate (NVE) based on Landsat imagery from 1999 to 2006 (Andreassen and Winsvold, 2012; Winsvold et al., 2014; digital data available from NVE, 2016; or the Global Land Ice Measurements from Space (GLIMS) database: GLIMS and NSIDC, 2012). Glaciers cover $1522 \mathrm{~km}^{2}$ or roughly $1.5 \%$ of our study area. This includes 1575 ice bodies ranging from small perennial ice patches of just over $0.01 \mathrm{~km}^{2}$ in size to the largest outlet glaciers $\left(>40 \mathrm{~km}^{2}\right)$ of the Jostedalsbreen ice cap. Fifty percent of the glacierized surface in southern Norway consists of glaciers with $<5 \mathrm{~km}^{2}$ spatial extension and $20 \%$ of the glacier area of ice patches smaller than $<1 \mathrm{~km}^{2}$. Some maritime glaciers advanced in the 1990s while glaciers located in more continental climate showed mainly frontal retreat (Nesje et al., 2008; Andreassen et al., 2005). After a culmination in 2000 , most of the monitored glaciers in Norway experienced net mass deficit (Kjøllmoen et al., 2011; Andreassen et al., 2016).

\subsection{ICESat}

ICESat GLAS was a single-beam spaceborne laser altimeter operational between February 2003 and October 2009, sampling the surface elevation of the Earth within roughly $70 \mathrm{~m}$ footprints during two to three observation periods each year of about 1 month each (Schutz et al., 2005). The laser footprints have $172 \mathrm{~m}$ spacing along-track, and approximately $42 \mathrm{~km}$ cross-track spacing between 91-day repeat reference orbits at $61^{\circ}$ latitude (Fig. 1). Cross-track spacing increases at lower latitudes, making polar areas in principle more favourable for ICESat applications. Note that our study area already lies in the polar acquisition mask of the ICESat mission at $>59^{\circ} \mathrm{N}$, where the off-nadir pointing mode enabled near repeats of the tracks (ca. $\pm 150 \mathrm{~m}$ ), in contrast to a nominal orbit repeat precision of $\pm 1000 \mathrm{~m}$ for midlatitudes (Schutz et al., 2005). In accordance with what Kääb et al. (2012) found to be the most suitable product for mountain glacier analyses, the ICESat data set used was GLAS/ICESat L2 Global Land Surface Altimetry HDF5 data (GLAH14), release 33 (Zwally et al., 2012). For GLAH14, elevation values were not changed between releases 33 and 34 (NSIDC, 2014). The data contain quality attributes and elevation corrections for each footprint. These attributes include a waveform saturation flag (attribute sat_corr_flag) to indicate saturation of the sensor when recording the returned pulse and a correction for the potential bias in extracted elevations from these saturated waveforms (attribute d_satElevCorr). The flags and corrections are intended for improving elevation accuracy on ice sheets (the original main purpose of the mission) and are not necessarily valid in rough mountain topography (NSIDC, 2012).

\subsection{Reference data}

The reference elevation data sets used are the national DEMs provided by the Norwegian Mapping Authority (further referred to as Kartverket) in 10 and $20 \mathrm{~m}$ spatial resolution (http://data.kartverket.no). In mountain areas, the Kartverket DEMs are based on source data at 1:50000 map scale including elevation contours at $20 \mathrm{~m}$ equidistance, resulting in a nominal absolute vertical accuracy of $\pm 4-6 \mathrm{~m}$ (defined as the standard deviation of elevation; Kartverket, 2016). Using the source date stamp of elevation contours as a proxy, the age of the DEMs was found to be highly variable geographically, ranging from 1978 to 2009 on southern Norwegian glaciers, and from 1961 to 2011 on non-glacierized areas.

For the Hardangervidda area and up to approximately $60.3^{\circ} \mathrm{N}$, the global DEM from the Shuttle Radar Topography Mission (SRTM, Farr and Kobrick, 2000) is available at $3 \mathrm{arcsec}$ resolution (corresponding to $93 \mathrm{~m}$ in $y$, and $45 \mathrm{~m}$ in $x$ direction at $60^{\circ} \mathrm{N}$ ) from the U.S. Geological Survey (https://dds.cr.usgs.gov/srtm/; NASA JPL, 2013). The SRTM DEM used here is based on C-band radar data acquired in February 2000 and consists of a composite of four or more overpasses at latitudes that far north (Farr et al., 2007). The absolute vertical accuracy of the mission is stated as $16 \mathrm{~m}$ (defined as 1.6 times the standard deviation of the error budget throughout the entire mission; Rabus et al., 2003) but found to be in the range of a few metres compared to ICESat elevations (Carabajal and Harding, 2006). The SRTM DEM featured as the reference DEM of choice for previous ICESat glacier trend analyses (e.g. Gardner et al., 2013; Kääb et al., 2012). Unfortunately, it does not cover glaciers visited by more than one ICESat overpass in southern Norway. Thus, in this study, the SRTM non-void filled elevation data only serves as alternative reference DEM for land samples.

For parts of the non-glacierized Hardangervidda plateau, high-resolution lidar DEMs were provided by NVE (Melvold and Skaugen, 2013). The data consist of six east-westoriented $80 \mathrm{~km}$-long stripes of $500 \mathrm{~m}$ width and cell size of $2 \mathrm{~m}$, flown on 21 September 2008 (minimum snow cover, leaf-off conditions). Data sets were available as highresolution gridded DEMs. From comparison to a kinematic ground GPS survey carried out in April 2008, Melvold and Skaugen (2013) found the absolute elevation errors of the lidar data set to range from -0.95 to $+0.51 \mathrm{~m}$, with a mean error of $0.012 \mathrm{~m}$ and a standard deviation of $0.12 \mathrm{~m}$.

Yearly net surface mass balance estimates from in situ measurements of eight glaciers within the study area (see the NVE report series "Glaciological investigations in Norway"; Kjøllmoen et al., 2011) were used as a reference for glacier behaviour during the ICESat acquisition period. The data series are the product of the recent homogenization of in situ measurements with geodetic measurements (Andreassen et al., 2016) and are available from http://glacier.nve.no/viewer/ CI (NVE, 2016). 


\section{Methods}

ICESat data points from the end of the hydrological year (autumn campaigns) are treated as a statistical sample of glacier surface elevations in southern Norway. We follow the double differencing method described by Kääb et al. (2012) where differences between ICESat elevations and a reference DEM (hereafter referred to as dh) are analysed. Direct comparison of ICESat elevations of different years, as done for larger Arctic glaciers and ice caps (plane-fitting methods, e.g. Howat et al., 2008; Moholdt et al., 2010), is not possible for small mountain glaciers. These methods assume a constant slope of the ice surface within the spatial variability of ICESat repeat ground tracks, which is not given for small mountain glaciers. The use of a reference DEM instead takes into account the more complex surface topography of small glaciers. When compared to elevations from a reference data set of a different source date, the $\mathrm{dh}$ will be negative if the surface has lowered over time between the DEM source date and ICESat acquisition time, and positive if the surface has risen. Differences should be zero if the surface elevation was constant, such as over stable ground. Uncertainties in elevation measurements of both data sets, not least as a result of rough terrain within the $\sim 70 \mathrm{~m}$ circular ICESat footprint, raise the need for sufficiently large statistical samples to reduce the effect of random errors. The evolution of dh over time is used to investigate surface elevation change trends over the ICESat acquisition period 2003-2008. (The 2009 autumn campaign is excluded due to low spatial coverage before complete ICESat failure.) Note that ICESat captures a signal of volumetric balance that results from surface elevation changes rather than mass change directly. The same is also the case where geodetic mass balances are obtained from DEM differencing, which is a widely used method. Comparison of ice surface elevation change trends with in situ measurements provided in metres water equivalent ( $m$ w.e.) requires unit conversion that depends on ice density. To validate the ICESat-derived trends, we back-converted the in situ data using the same density as NVE used for mass to volume conversion of geodetic data (Andreassen et al., 2016). It is based on the findings of Huss (2013), who suggested a value of $850 \pm 60 \mathrm{~kg} \mathrm{~m}^{-3}$ as an average integrated over an entire glacier. (See also the discussion and density scenarios in the Supplement of Kääb et al., 2012.)

\subsection{Pre-processing and filtering of ICESat data}

ICESat surface elevations (height above reference ellipsoid) were converted to Norwegian height above mean sea level, in accordance with national DEM elevations. The ca. 170000 data points within the study area were classified into ice and land footprints using the glacier outlines provided by NVE. Footprints lying partially on glaciers, i.e. with footprint centre locations within $40 \mathrm{~m}$ of NVE glacier borders (both inand outside original outlines), were classified as ice borders and excluded from further analysis. Apart from avoiding a mixed land/ice elevation signal from partly ice-covered $70 \mathrm{~m}$ footprints this also accounts for the spatial uncertainty of glacier outlines and their potential change over time. For glacier analyses, spring and summer campaigns were excluded to avoid biased trends due to yearly varying snow heights (see argumentation in Kääb et al., 2012, 2015), and the 2009 autumn campaign was excluded due to insufficient spatial coverage caused by weakening of the laser over time. To account for differences in spatial distribution and potential elevation changes due to onset of snowfall, the split autumn campaign of October 2008 (laser 3K, ran out of power before the campaign was completed) and December 2008 (laser 2D, completion of the autumn 2008 campaign) were treated separately where appropriate. Land footprints on fjords and lakes were filtered out using shoreline data provided by the Norwegian Mapping Authority, as water levels may vary (tides, hydropower reservoirs).

Reference DEMs were corrected for elevation bias and spatially co-registered with ICESat (see Sect. 3.2). Reference elevations for each footprint were extracted from the DEMs by different statistical means: footprint centre elevation, mean, median, mode (rounded to the metre/decimetre for the Kartverket/lidar DEMs), inverse distance-weighted (IDW, linear weighing, i.e. power 1), and bilinear interpolation of elevation of DEM grid cells within an assumed circular footprint with $35 \mathrm{~m}$ radius (i.e. four grid cells for SRTM, 12 for Kartverket 20 m, 38 for Kartverket $10 \mathrm{~m}$ and $\sim 960$ for the lidar DEM).

The elevation differences between ICESat and the Kartverket DEM were analysed to denote a cut-off threshold for maximum elevation differences. Mean dh were found to be $\sim-0.5 \mathrm{~m}$ for land, and $\sim-2 \mathrm{~m}$ for ice samples (i.e. ICESat elevations are lower than reference elevations over glaciers). Using bootstrapping methods and histogram analysis for thresholds between 50 and $250 \mathrm{~m}$ for $|\mathrm{dh}|$, we found that a cut-off threshold of $\pm 100 \mathrm{~m}$ dh effectively removed cloud measurements. Footprints with $|\mathrm{dh}|>$ threshold were excluded from all further analyses. The conservative threshold allows for uncertainty in elevation measurements of both data sets (land and ice), while allowing for slightly skewed dh distributions. It ensures all negative dh from glacier surface lowering between DEM acquisition date and ICESat elevation measurements are included while removing footprints on clouds (false positive dh).

Robust linear regression (we used Matlab's robustfit function with default parameterization) through all individual samples was performed to find a linear trend for surface elevation change over time. Robust methods iteratively reweigh least squares to find and exclude outliers until regression coefficients converge. For our ice trends we found that ca. $2-3 \%$ of the samples received weight 0 and were thus essentially removed as outliers. As an alternative trend estimate, we used the gamlss package in $\mathrm{R}$ (www.gamlss.org) to perform regression using a fitted $t$ distribution. The $t$ fit 
accounts for a larger number of outliers in our distribution of dh (Fig. 2) compared to a normal distribution (Lange et al., 1989).

\subsection{Subpixel shifts and corrections applied to the reference DEMs}

Based on dh of autumn campaign land samples, elevation bias, and spatial shifts between ICESat and the reference DEMs were quantified. The non-systematic spatial shifts of subpixel magnitude and biases were corrected where possible. No corrections were applied to the lidar DEM. For the Kartverket and SRTM DEMs, directions and magnitudes of the shifts seemed to vary highly, also within single DEM tiles. Automated co-registration using the methods of Nuth and Kääb (2011) was performed to correct an overall $20 \mathrm{~m}$ shift south and $-2.6 \mathrm{~m}$ vertical offset of the SRTM DEM, compared to ICESat. However, additional shifts and biases that seem present in subunits of the SRTM DEM could not be corrected. For the Kartverket DEMs, dh were found to be elevation-dependent (more negative with increasing elevation above sea level $H$ ). The relationship is in the order of decimetres per $100 \mathrm{~m}$ elevation and applies to both the 10 and $20 \mathrm{~m}$ DEM as both are based on the same source data. To account for this vertical bias, a correction term $c_{H}$ was applied to individual elevation values of both Kartverket DEMs:

$c_{H}=0.882-0.00158 \cdot H$.

Automated co-registration of the individual nominal Kartverket DEM tiles $(50 \times 50 \mathrm{~km}$ and $100 \times 100 \mathrm{~km}$ for the $10 / 20 \mathrm{~m}$ DEMs respectively) was not applied systematically as it did not result in an overall positive effect. This is due to overlying shifts of (unknown) production subunits within single tiles in different directions. To account for the apparently consistent vertical offsets in some areas, correction terms for each individual nominal tile $\left(c_{\text {tile }}\right)$ and the indicative source date $\left(c_{\text {date }}\right)$ of the Kartverket DEM were computed (after $c_{H}$ correction). For each nominal DEM tile the median land difference between ICESat and the Kartverket DEM was removed; alternatively the same was done for each temporal unit of the Kartverket DEM. Both corrections are meant to remove vertical spatio-temporal biases and bias patterns in the reference DEM. The values of the corrections correspond to the median $\mathrm{dh}$ of all filtered land footprints at minimum snow cover (autumn campaigns only) per tile and date and are in the order of $\pm 1 \mathrm{~m}$ per tile, and $\pm 5 \mathrm{~m}$ per date respectively. Potential physical causes such as vertical uplift due to post-glacial rebound in Scandinavia are in the order of decimetres for the last half century and cannot explain the large differences between ICESat and reference elevations on land surfaces. As a proxy for the reference DEM source date per ICESat footprint we used the time stamp of the closest elevation contour line to each footprint (elevation contours are the most important input data set the Kartverket DEMs are based on; Kartverket, personal communication, 2013). However, these correction terms are an approximate only. Spatially confined units with unique source data/firm update dates do not strictly exist and the total DEM is thus a product of spatio-temporal merging (Kartverket, personal communication, 2013), not untypical for DEMs from national mapping agencies.

For glaciers, spatially varying DEM source dates add additional uncertainty. Surface elevation difference between Kartverket DEM acquisition and the first ICESat acquisitions varies for individual glaciers, resulting in different (additional) offsets for each glacier. A correction term $c_{\text {glac }}$ for this effect was computed from the median dh of ice samples at the time of minimum snow cover (autumn campaigns only) for each individual glacier, as classified using the NVE glacier inventory. The values of $c_{\text {glac }}$ range from -20 to $+15 \mathrm{~m}$ and reflect mainly vertical glacier changes between the DEM and ICESat dates in this study. For other areas, potentially other vertical biases from DEM production, such as height datums or signal penetration, could be addressed in a similar way. The latter are not relevant for the photogrammetric methods behind the Kartverket DEM, but may be relevant for radar wave penetration within the SRTM DEM.

\subsection{Sample representativeness and trend sensitivity}

In order to relate measured dh to actual net glacier mass balance, the ICESat sample has to mirror key characteristics of the area/terrain with respect to glacier driving processes. We assessed the representativeness of the ICESat glacier sample for the study area in terms of average elevation, slope, aspect, spatial distribution of the footprints, glacier size, and age of the reference DEM. Representativeness with respect to terrain parameters was tested by comparing the sample distribution to the respective distributions of all glaciers in southern Norway (we used all Kartverket DEM cells within the glacier mask). This was done both for the entire ICESat sample and for individual campaigns. Consistency in terms of reference DEM age distribution per campaign was assessed using the source date of the closest contour line for each sample as a proxy. Additionally, the size of the glaciers sampled by ICESat was compared to the entire glacier population of southern Norway.

To assure robustness of fitted glacier surface elevation difference trends, the effect of different data subsets and elevation corrections applied to either of the data sets were assessed. Subsets were created by including/excluding (a) sets of footprints, as those classified as ice border, with specific DEM time stamps, or samples flagged as fully saturated (attribute sat_corr_flag $\geq 3$ ); (b) spatial subsets, e.g. of glaciers east and west of the main water divide; and (c) entire campaigns. The elevation corrections assessed include ICESat saturation elevation correction (attribute d_satElevCorr) in addition to the correction terms per Kartverket DEM tile/source date/glacier described above $\left(c_{\text {tile }}, c_{\text {date }}, c_{\text {glac }}\right)$. Very intentionally, we did not divide our samples into footprints only in the accumulation or ablation parts of the 

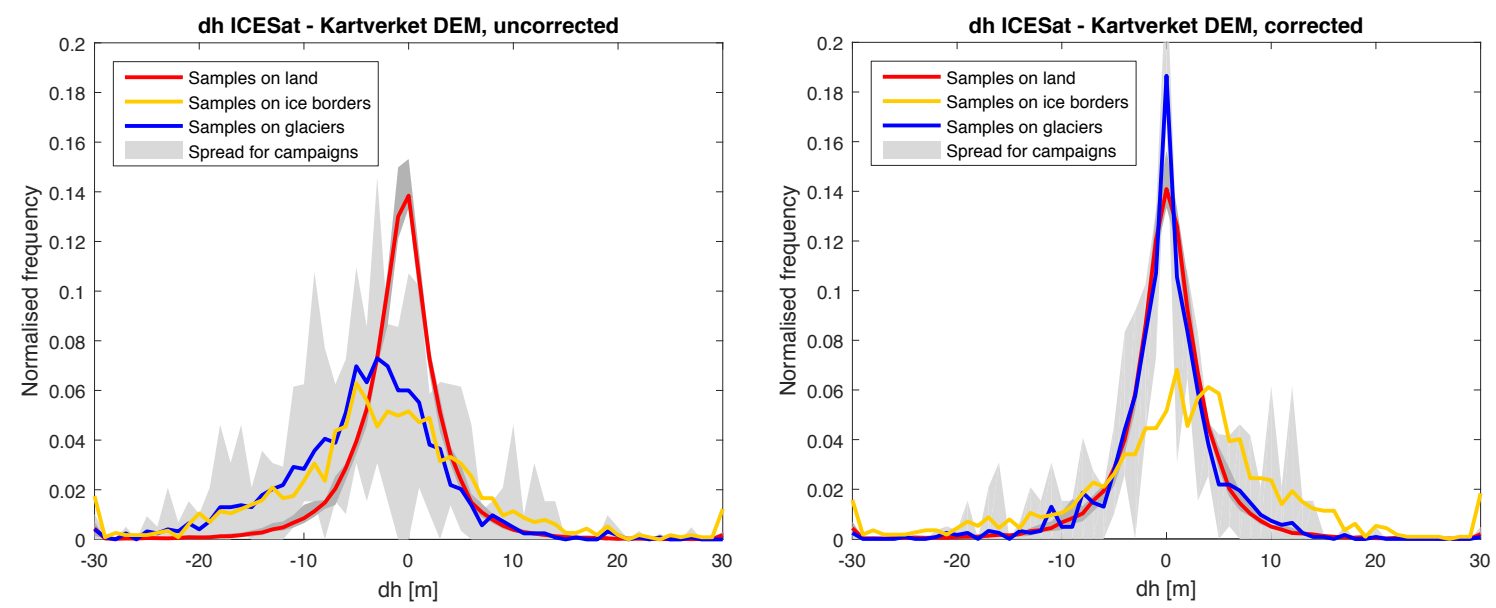

Figure 2. dh of land and ice (autumn campaigns 2003-2008) for the uncorrected Kartverket $10 \mathrm{~m}$ DEM elevations (left) and with DEM elevation corrections $\left(c_{\mathrm{tile}}, c_{H}\right)$ and per-glacier correction $\left(c_{\mathrm{glac}}\right)$ applied (right). The grey spreads shows the range of distributions for ice (wide spread, light grey) and land dh (narrow spread, darker grey) of individual campaigns.

glaciers respectively. In order to capture a signal that translates into geodetic mass balance, it is essential to sample the entire glacier to consider both surface elevation changes from ice melt/gain and dynamic glacier flow. If this is not ensured, the condition of mass continuity is violated, and it would thus be physically incorrect to draw conclusions on glacier mass balance based on surface elevation trends from a subset of samples in the ablation/accumulation areas only. The influence of separating footprints over ice and snow/firn for separate density scenarios is discussed in Kääb et al. (2012).

\section{Results}

\subsection{ICESat sample overview}

Roughly $75 \%$ of the nearly 170000 ICESat footprints over southern Norway contains valid information of the Earth's surface elevation (125312 samples after removal of footprints on clouds and water surfaces, see Table S1 in the Supplement). Thereof, $2.6 \%$ lie fully on glaciers (vs. an additional $0.9 \%$ that were classified as ice borders). For glacier analyses, considering autumn campaigns only, a total of 1268 ice and 48854 land samples remain. These numbers are reduced by $2.8 \%$ (ice) and $1.6 \%$ (land) only by excluding the weak autumn 2009 campaign. Dh of the remaining samples rarely exceed $\pm 10 \mathrm{~m}$. The dh are $t$ distributed with a narrower peak but heavier tails compared to a normal distribution. Before application of the correction terms to the Kartverket reference DEM, the dh distributions of ice and ice border samples are considerably wider and in average more negative than land dh (Fig. 2, left). After application of $c_{H}, c_{\text {tile }}$ and $c_{\text {glac }}$ correction terms, 94 and $95 \%$ of the ice, and land autumn samples respectively, but only $80 \%$ of ice border autumn samples show less than $10 \mathrm{~m}$ absolute eleva- tion difference between ICESat and the (corrected) Kartverket $10 \mathrm{~m}$ DEM elevations (Fig. 2, right).

The spatial distribution and number of ICESat samples is not constant over time and decreases to as little as $10 \%$ of the number of samples of the autumn 2003 campaign, which includes most samples of all campaigns (427 ice samples). In autumn 2009, only 35 ice samples (vs. 792 land samples) remain over southern Norway. Other autumn campaigns with very small sample numbers are 2005 (65 ice samples) and 2008 (24 and 24 ice samples for the October and December campaigns respectively). These periods with particularly few samples correspond to campaigns with few orbits flown $(2008,2009)$ or heavy cloud coverage (2005).

Of the ice samples, 128 lie on glaciers that were only sampled during a single autumn campaign. After the application of $c_{\text {glac }}$, any glacier elevation change signal from these single overpass samples is cancelled out. The majority of these (113) occurred during the autumn 2003 campaign due to a transition between two different orbit patterns in the middle of the campaign (Schutz et al., 2005). The single overpass samples with on average $0 \mathrm{~m}$ dh may thus flatten out derived trends and were excluded where appropriate.

\subsection{Representativeness of ICESat glacier sample}

The entire ICESat glacier sample appears representative in terms of elevation, aspect, slope, spatial distribution, and glacier area of the glaciers sampled (Fig. 3 and Fig. S1 in the Supplement). Compared to the frequency histogram of the entire glacierized surface in southern Norway, ICESat slightly oversamples east-facing glaciers and underrepresents the glacierized area in the south-western parts of the area of interest due to the orbits not covering the Folgefonna ice cap (Fig. 1). However, these deviations are of the same magnitude or less than deviations of the frequency his- 

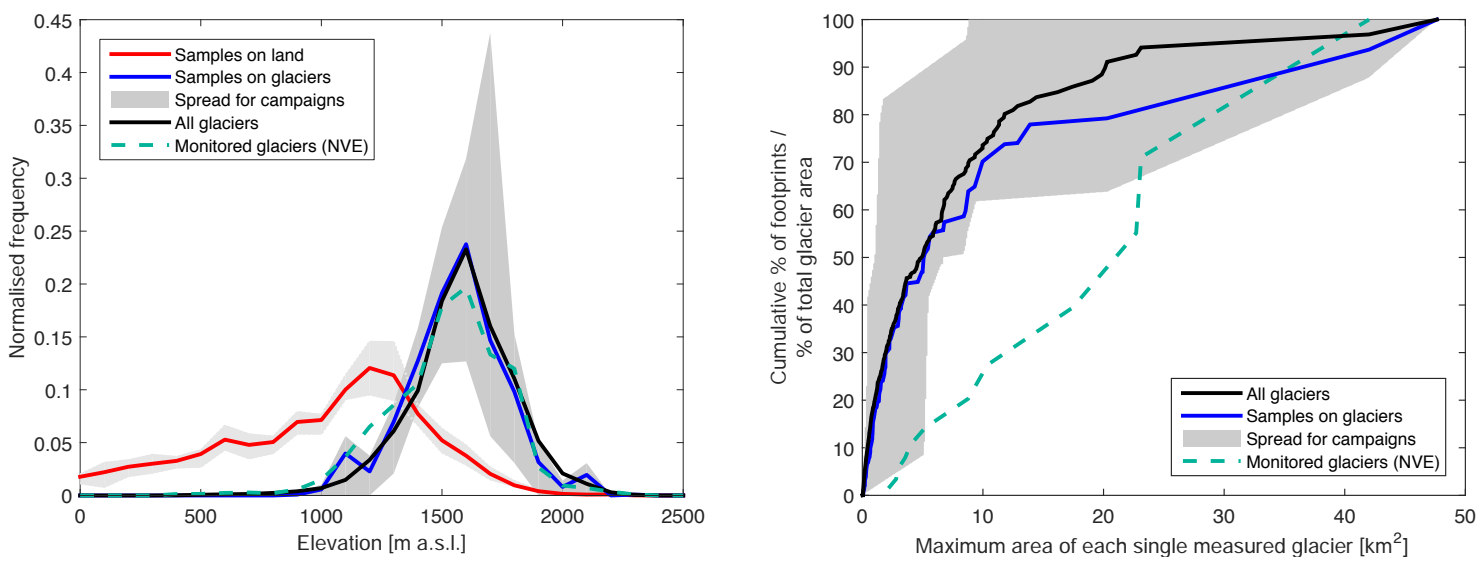

Figure 3. Representativeness of 2003-2008 ICESat autumn campaign samples in terms of footprint elevation (left) and area of glaciers sampled (right), compared to the entire glacierized surface in southern Norway and monitored glacierized surface (mass balance program by NVE). The grey spread encompasses the distributions of single ICESat autumn campaigns; where it is wide, the difference between individual campaigns is the largest. Reading example for glacier area comparison: $50 \%$ of the entire glacierized surface in southern Norway is made out of glaciers $<5 \mathrm{~km}^{2}, 50 \%$ of the glacierized surface where NVE runs a mass balance program is made of glaciers $<23 \mathrm{~km}^{2}$, and $50 \%$ of all ICESat autumn ice samples lie on glaciers $<5.1 \mathrm{~km}^{2}$.

tograms of the glacierized area monitored in situ by NVE. Of the individual campaigns (autumn campaigns 2003-2008 shown within the grey spread), those with the fewest samples deviate the most, but still follow the distribution of the full data set. Variability between campaigns is largest (wide grey spread) for easting, also for land samples, due to the sensitivity of the sample to exclusion of entire orbits (due to shorter campaigns/cloudy weather). The two autumn 2008 campaigns are only representative if combined, as only a subset of orbits was flown in October and December. The autumn 2009 campaign was found to include ice samples for one overpass only (orbit 30, Fig. 1), resulting in sampling of only Myklebustbreen and Haugabreen, an outlet glacier of the Jotunheimen ice cap. All other campaigns have 5-13 different orbits with glacier samples. Severe spatial concentration and poor representation of southern Norwegian glaciers confirmed that also for our study area, the entire autumn 2009 campaign should be excluded from further analyses.

Of the 1575 ice bodies in southern Norway, 96 or $6.1 \%$ are hit by at least one footprint of our filtered ICESat ice sample. While not the same glaciers are sampled each year, for all autumn campaigns except for 2009, footprints are spread on 17 (2008) to 77 (2003) different glaciers across the study area. Our ICESat footprints seem to capture small ice bodies according to their relative share of the total glacierized area: $47 \%$ of the samples lie on glaciers smaller than $5 \mathrm{~km}^{2}, 17 \%$ on ice bodies $<1 \mathrm{~km}^{2}$ (Fig. 3, right). Only the (combined) autumn 2008 campaign samples no glacier $>12 \mathrm{~km}^{2}$, and the ice bodies sampled in December 2008 are distinctively smaller than those sampled in October in 2008. The smallest glacier within the NVE mass balance programme in the area is $2.2 \mathrm{~km}^{2}$ large.

\subsection{Error sources and corrections for ICESat and DEM elevations}

Elevation errors in the DEMs were found to exceed ICESat footprint elevation uncertainty as well as the magnitude of corrections available in the ICESat products. ICESat elevation corrections from effects of waveform saturation (attribute d_satElevCorr) are in the range of decimetres; all other elevation corrections within the data set are even smaller. Application of ICESat correction terms had no notable effect on dh distributions. The relative share of saturated samples (parameter satCorrFlag $\geq 3$ in the data set) varies between 5 and $40 \%$ for the different campaigns and is up to $15 \%$ higher for ice than for land. In contrast to the findings of Kääb et al. (2012) for high-mountain Asia, we found the number of saturated samples to decrease over time to as little $0-2 \%$ for the last three acquisition campaigns (laser 2D-2F). Filtering increased the relative share of saturated samples by on average $5 \%$, and mean absolute dh (after filtering) are smaller for saturated footprints than for non-saturated ones (95\% confidence) for both land and ice, whether or not saturation correction was applied to the $\mathrm{dh}$. Saturated samples were therefore not removed from the data set for trend computation, and saturation correction was not applied.

In contrast to the ICESat elevation values that seem robust without any corrections, elevation correction terms applied to the Kartverket reference DEMs significantly narrowed dh distributions (Fig. 2, right). The elevation-dependent correction term $c_{H}$ successfully removed skewness towards more negative $\mathrm{dh}$ in dh distributions, and per-glacier correction $c_{\text {glac }}$ clearly caused a major reduction in ice dh. The correction terms $c_{\text {tile }}$ and $c_{\text {date }}$ were found to be interchangeable 
and resulted in minor improvements only on land and ice dh distributions. For single footprints, uncertainty in reference DEM elevation is on the order of metres.

Looking at single footprints, reference DEM elevations differ by decimetres to metres between the different statistical measurements (mean, bilinear interpolation, etc.) applied to DEM grid cells within the ICESat footprint, for one and the same DEM. The method chosen matters most for the SRTM DEM with only four contributing cells, but differences resulting from the chosen elevation extraction method - from the perspective of a single footprint - are also higher for the high-resolution lidar DEM with ca. 960 contributing cells than for the 10/20 m Kartverket DEMs. However, for larger sample numbers, these differences cancel out and dh distributions for reference elevations from the same DEM, but different elevation extraction methods, are approximately the same (Fig. 4). Summarizing statistical methods appear to produce slightly narrower dh distributions than centre DEM elevations only but the difference between the curves is not significant. Mode elevations differ most from reference elevations computed by the other methods, also for the $2 \mathrm{~m}$ lidar DEM. We based our further analyses on median DEM elevations per footprint, or bilinear interpolation in the case of the low-resolution SRTM DEM.

Reference elevations between DEMs from different sources varied greatly. For the 184 autumn samples on Hardangervidda where all four reference DEMs were available, the lidar DEM matched ICESat elevations closest with a mean vertical offset of $0.03 \mathrm{~m}$ and a narrow dh distribution (Fig. 4). Elevation differences from the co-registered SRTM DEM are skewed with a heavier tail towards negative dh. Distributions of the (corrected) Kartverket DEMs, dating back to the 1970s in eastern parts of the Hardangervidda, are particularly wide for this subset of samples, including an average vertical offset of $-1.3 \mathrm{~m}$. For other spatial subsets, widths and vertical offsets of dh distributions of the SRTM and Kartverket DEMs vary to the same degree in a seemingly random way. Distributions of dh based on the 10 vs. $20 \mathrm{~m}$ Kartverket DEMs were the same, also for other spatial subsets, and no improvement in elevation precision per footprint could be found from the finer grid resolution.

Analysis of the DEM source dates for ice samples of the different campaigns (Fig. 5) shows the representativeness of our sample in terms of Kartverket reference DEM age distribution. Seventy percent of the samples have reference elevations from 2008 to 2009 (further termed "post-2000”), and only approximately 20 and $10 \%$ date back to the 1990s and 1980s ("pre-2000") respectively. Only two campaigns divert from this distribution: in autumn $2005,60 \%$ of the ice samples have old reference DEMs, and in 2009, all ice samples have very recent reference elevations from 2008 to 2009. For the split autumn 2008 campaign, all but one of the October samples fall on reference DEMs from 2008, while $80 \%$ of the December samples have pre-2000 DEMs. If using uncorrected Kartverket DEM elevations, pre-2000 dh are signifi-

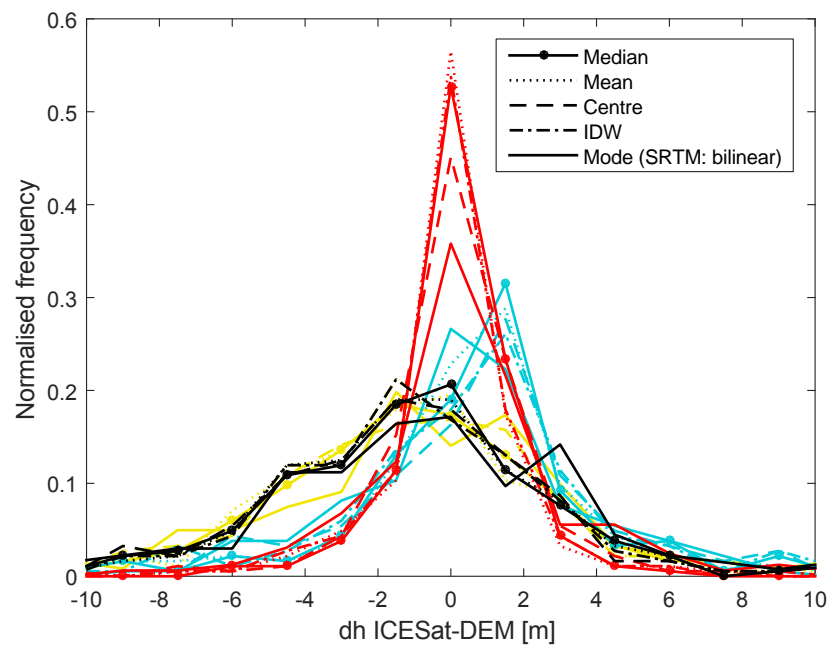

Figure 4. Graph shows dh from different reference DEMs and statistical measures to summarize elevations within footprints (184 land samples): lidar $2 \mathrm{~m}$ (red), Kartverket $10 \mathrm{~m}$ (black) and $20 \mathrm{~m}$ (yellow), SRTM $\sim 90 \mathrm{~m}$ (blue, bilinear interpolation shown instead of mode).

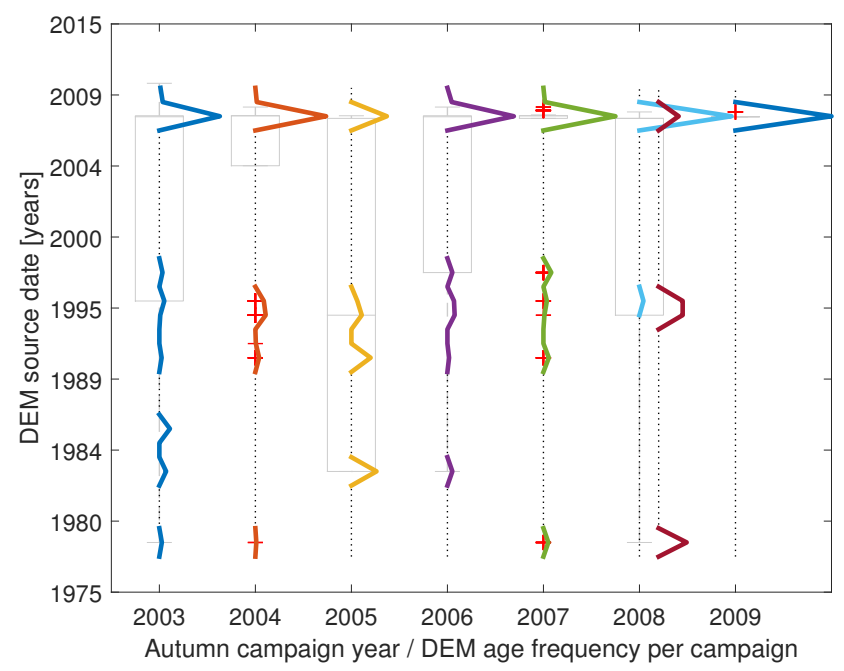

Figure 5. DEM source date distributions for ICESat autumn campaign samples on glaciers. The box plots emphasize the average DEM age per campaign while the frequency histograms (coloured curves) reflect the relative DEM age distributions. In 2008, the October (blue) and December (brown) campaigns are shown separately (frequency histogram) and grouped (box plot).

cantly more negative (mean $\mathrm{dh}:-7.3 \mathrm{~m}$ ) than post-2000 dh $(-3.1 \mathrm{~m})$. The per-glacier correction $c_{\text {glac }}$ completely reconciles the two distributions as seen in Fig. 2. Note that $c_{\text {glac }}$ treats glaciers as spatial units with consistent source data set. Where this is not given - and parts of a glacier surface are mapped on different dates or with different methods - the correction will be only partially effective. 

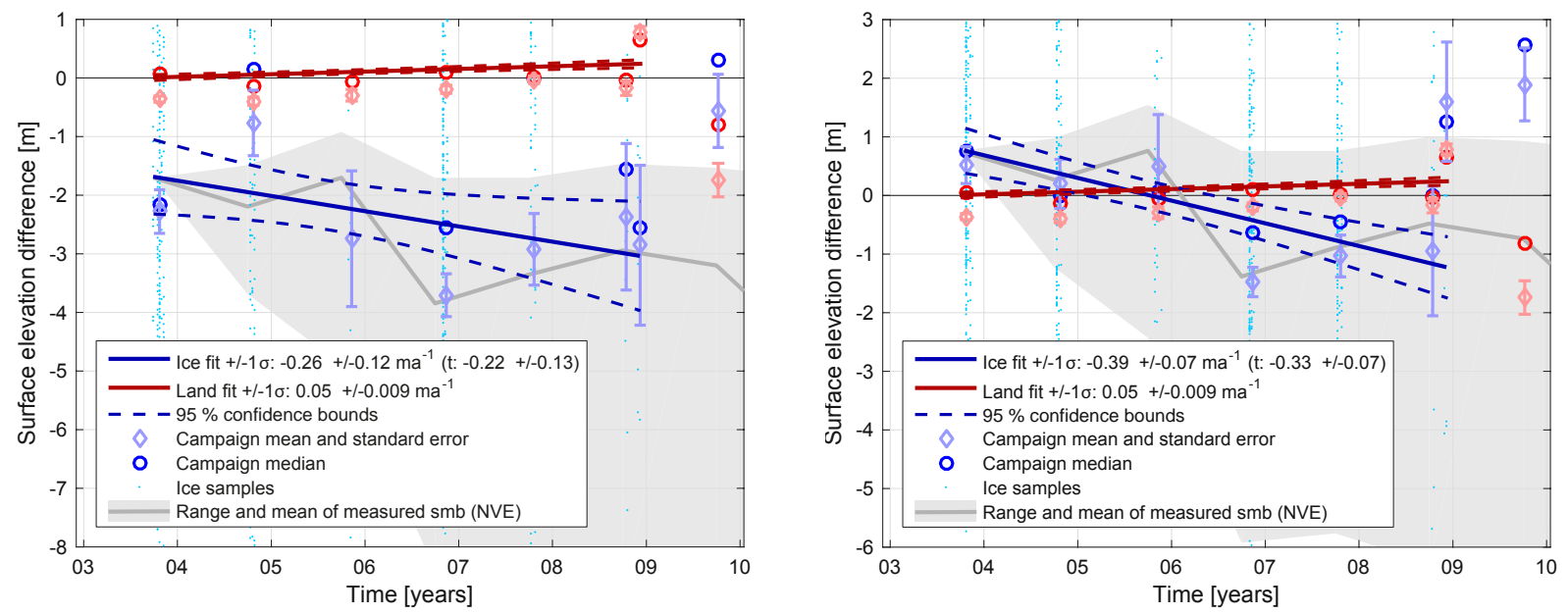

Figure 6. Surface elevation difference trends for land (red) and ice (blue) samples respectively, for autumn campaigns 2003-2008. Left: per-tile and -elevation corrections $\left(c_{\text {tile }}, c_{H}\right)$ applied, 1233 samples. Right: per-tile, -elevation and -glacier correction $\left(c_{\text {glac }}\right)$ applied, 1105 samples. Trends are computed from individual dh samples using robust linear regression. Campaign median and mean \pm standard error per campaign and class are shown to indicate the variability in dh per campaign. The grey spread corresponds to the measured range of cumulative surface mass balances of eight glaciers in the area, reconverted to ice volume changes using a density of $850 \mathrm{~kg} \mathrm{~m}^{-3}$ (Andreassen et al., 2016), and their area-weighted mean. The data provided by NVE are based on in situ and geodetic measurements.

\subsection{Glacier thickness trends}

We find a glacier surface elevation change of $-0.39 \mathrm{ma}^{-1} \pm 0.07$ standard error $(1 \sigma)$ for the years 2003-2008 (Fig. 6, right) with all corrections to DEM elevations applied when samples on glaciers covered by only a single autumn overpass were excluded. The trend slope decreases slightly to $-0.34 \pm 0.062 \mathrm{ma}^{-1}$ when such single-overpass samples are included. Using a $t$ fit instead, we found trends in general to be less sloping than robust trends for the same sample/set of applied corrections, and obtained alternative ice trend estimates of $-0.33 \pm 0.07$ and $-0.27 \pm 0.061 \mathrm{ma}^{-1}$ on the same data sets. Campaign means are more negative than campaign medians, which indicates slightly skewed dh distributions for both ice and land samples. Land campaign means/medians follow the near-zero trend as computed from all individual samples very closely $\left(0.05 \pm 0.009 \mathrm{ma}^{-1}, t\right.$ fit: $\left.0.04 \pm 0.009 \mathrm{~m} \mathrm{a}^{-1}\right)$. An exception to that is the December 2008 campaign which indicates surface rise in contrast to the October 2008 campaign due to onset of winter snowfall at higher elevations. Exclusion of the December 2008 campaign effectively sets the land trend to zero and renders the ice trend more negative. On the other hand, however, the December ice samples are required for the autumn 2008 campaign to be representative (see Sect. 4.1). Correction of December samples for increasing snow depth (estimated from October to December land dh differences per elevation) also removes the land trend, but does not affect the ice trend. If the per-glacier dh correction $c_{\text {glac }}$ is not applied, the ice trend is reduced and uncertainty increases to $-0.26 \pm 0.12 \mathrm{ma}^{-1}$
( $t$ fit: $-0.22 \pm 0.13 \mathrm{ma}^{-1}$ ). This decrease of thickness loss rate is due to the mixing of older and newer dates of the reference DEM that introduces biased dh and thus dilutes trends. Without the correction, ice campaign medians/means of uncorrected samples do not follow the assumed linear trend well and the standard errors of the campaign means just about overlap with $95 \%$ trend confidence bounds (Fig. 6, left). Deviation and uncertainty are largest for campaigns with few samples and non-representative DEM age distribution: 2005, October/December 2008 (split), and 2009 (excluded from trends). If ICESat trends were fitted through campaign medians instead of individual samples, these biased/non-representative campaigns would get the same weight as all other campaigns and, consequently, have more power to alter the derived trend. This stresses that ICESat trends over glaciers should be computed based on the entire footprint sample, not based on campaign statistics (e.g. median dh) that give campaigns disproportionate weight compared to the actual number of samples included in that campaign.

After applying the per-glacier vertical correction $c_{\text {glac }}$ to the ice dh, means/medians of single campaigns follow the pattern of NVE's in situ mass balance measurements remarkably well. The range of cumulative net surface mass balances, converted to surface elevation changes (Huss, 2013) of eight glaciers in the study area, is shown as a grey spread in Fig. 6. Note that these data are a product of the recent homogenization of in situ data of Norwegian glaciers with geodetic measurements (Andreassen et al., 2016) and thus differs from more positive glacier mass balance curves published earlier. For some of the studied glaciers, the data ho- 
mogenization suggests stronger mass loss and no or more moderate mass surplus for the glaciers with positive cumulative surface mass balance in the studied time period. Campaign means are shifted up with the ice trend line crossing $0 \mathrm{~m}$ dh in autumn 2005 which corresponds to zero-elevation difference between ICESat and reference DEM considering decreasing sample numbers (autumn 2005 corresponds to the mean date of all ICESat samples used). Noteworthy is the 2005 autumn campaign which - only after correction - fits well with the reported positive net balance for five out of ten measured glaciers (Kjøllmoen et al., 2006). The 2009 campaign does not follow the trend or the in situ measurements, regardless of the application of $c_{\text {glac }}$, In situ measurements suggest moderately negative net surface mass balances for that year (Kjøllmoen et al., 2010).

The slopes of both land and ice trends are not significantly affected $\left(< \pm 0.01 \mathrm{ma}^{-1}\right.$ change in trend slope) by either DEM correction terms $\left(c_{H}, c_{\text {tile }}\right.$ and $\left.c_{\text {date }}\right)$, the use of alternative statistical measures to extract DEM elevations per footprint, or the application of saturation correction to ICESat elevations. Exclusion of saturated samples and application of saturation correction to the remaining dh flattens out ice trend slopes by $0.03 \mathrm{~m} \mathrm{a}^{-1}$ and increases uncertainty (see Table 1). Including ice border samples only affects the ice trend if $c_{\text {glac }}$ is not applied, but does not increase trend significance despite the increased sample number. If winter campaigns are included, the ice trend becomes considerably more negative $\left(-0.43 \pm 0.066 \mathrm{ma}^{-1}, t\right.$ fit: $-0.41 \pm 0.070 \mathrm{ma}^{-1}$. The same accounts for fitting a trend through winter campaign samples only $\left(-0.42 \pm 0.092, t\right.$ fit: $\left.-0.41 \pm 0.097 \mathrm{~m} \mathrm{a}^{-1}\right)$. Note that for comparability between winter and autumn trends single overpass samples are not excluded in the numbers here. The 2003 winter campaign had a different orbit pattern to later campaigns (Schutz et al., 2005). We found yearly varying snow heights of between 3 and $7 \mathrm{~m}$ on glaciers, and the maximum values in winter 2005 correspond well to the overall strongly positive winter mass balance of that particular year (Kjøllmoen et al., 2006). Ice trend slopes are considerably more sensitive to all changes in sample composition described above if $c_{\text {glac }}$ is not applied.

Continental glaciers east of the water divide show a more negative trend than coastal glaciers. The same is true for small (area $<5 \mathrm{~km}^{2}$ ) vs. large glaciers, and ice samples with pre-2000 vs. post-2000 reference DEM. The latter corresponds to an arbitrary subset in size (with a tendency of older reference DEMs for smaller glaciers) and spatial distribution of glaciers rather than a selection based on any physically meaningful criteria. The increases in trend slope amount to $50-150 \%$ between these respective subset pairs (Table 1). However, we could not find a significant relationship between dh magnitude and distance to coast. Exclusion/inclusion of entire campaigns was found to affect trends only for campaigns at either end of the ICESat acquisition period.
Note that subsets of samples of only accumulation/ablation zones, as well as certain elevation or slope classes, would also result in different trends (not shown). Such sample subsets can obviously not fulfil the requirement of representativeness for the entire glacier area and are thus not comparable to in situ glacier mass balance measurements. Glaciers that are not in balance adjust their geometry via glacier flow, which causes additional surface elevation changes that may be different for the accumulation and ablation parts of a glacier. Only sampling of the entire glacier(s) ensures that both elevation changes due to surface mass balance as well as glacier dynamics are included in the volumetric mass balance signal measured by ICESat.

The problem of biased trends due to non-representative spatial sampling by ICESat is illustrated well by the spatially clumped autumn 2009 campaign. The only glaciers that are sampled in 2009 have a strongly positive trend (Fig. 7, $+0.47 \pm 011 \mathrm{ma}^{-1}$, in total 181 samples from Myklebustbreen and Haugabreen for autumn campaigns 2003-2009). While this trend is based on fewer campaigns (missing data in 2005 and 2007, only 3 and 7 samples for the 2004/08 campaigns respectively), the trend slope is not unrealistic (2.05/0.14 m w.e. cumulative balance before/after data homogenization for nearby Nigardsbreen in 2003-2009; Kjøllmoen et al., 2009; Andreassen et al., 2016). The ICESat sample on these glaciers is representative (also for single campaigns) in terms of elevation, slope, aspect, and spatial distribution (within a single track that roughly follows the glacier flow line) compared to the entire glacier area of Myklebustbreen/Haugabreen from the reference DEM. The reference DEM for this area was updated in 2008 , resulting in a positive offset of the ice campaign mean in autumn 2009 (Fig. 6). The fact that these glaciers are not at all representative for the cumulative mass balance of the entire glacier population in southern Norway explains the large offset of the 2009 campaign mean to the 2003-2008 ICESat trend.

\section{Discussion}

\subsection{Representativeness}

When combined with reference elevations from a DEM, ICESat data provide realistic estimates for glacier surface elevation change in southern Norway. However, our results bring out the importance of ensuring representativeness of the sample as well as good control over biases in reference elevations.

The ICESat sample has to be representative not only in terms of terrain and topographic characteristics that govern glacier behaviour but also data quality aspects that vary spatially. Parameters with coarse spatial patterns have the largest biasing potential. Consequently, reference DEM quality and age, glacier area, and severe variations in spatial distribution of the samples were found to potentially have the largest 
Table 1. Trends and trend standard error (SE), as computed from different subsets and corrections applied to the data set $\left(c_{H}, c_{\text {tile }}\right.$ and $c_{\text {glac }}$ are applied unless specified otherwise). Footprints on glaciers sampled only during one autumn campaign are excluded except for the subsets marked with an asterisk, i.e. * corresponds to all 2003-2008 (autumn) ice samples. In bold are final estimates for the whole of southern Norway. Italicized are values for land samples.

\begin{tabular}{|c|c|c|c|c|c|c|}
\hline Data set & Correction/subset & Robust trend & $\mathrm{SE}(1 \sigma)$ & Samples & $t$ trend & $\operatorname{SE}(1 \sigma)$ \\
\hline ice & $\left(c_{H}, c_{\text {glac }}\right.$, only $>1$ overpass $)$ & -0.39 & 0.07 & 1105 & -0.33 & 0.07 \\
\hline land & $\left(c_{H}, c_{\text {tile }} / c_{\text {date }}\right)$ & +0.05 & 0.009 & 48089 & +0.04 & 0.009 \\
\hline ice & $\left(c_{H}, c_{\text {glac }}\right)$ all ice samples* & -0.34 & 0.062 & 1233 & -0.27 & 0.061 \\
\hline ice & $c_{\text {glac }}$ not applied* & -0.26 & 0.12 & 1233 & -0.22 & 0.13 \\
\hline ice & Dec 2008 excluded & -0.44 & 0.072 & 1085 & -0.37 & 0.071 \\
\hline land & Dec 2008 excluded & -0.003 & 0.010 & 44568 & -0.004 & 0.010 \\
\hline ice & Corr Dec 2008 & -0.4 & 0.07 & 1105 & -0.34 & 0.069 \\
\hline land & Corr Dec 2008 & +0.001 & 0.009 & 48089 & -0.003 & 0.009 \\
\hline ice & Incl 2009 & -0.25 & 0.065 & 1140 & -0.22 & 0.066 \\
\hline land & Incl 2009 & +0.03 & 0.008 & 48854 & +0.03 & 0.008 \\
\hline ice & Sat_corr applied, saturated samples excluded & -0.35 & 0.072 & 1001 & -0.3 & 0.075 \\
\hline ice & East of water divide & -0.55 & 0.14 & 242 & -0.54 & 0.14 \\
\hline ice & West of water divide & -0.36 & 0.08 & 863 & -0.29 & 0.08 \\
\hline ice & Pre-2000 DEM source date & -0.72 & 0.16 & 298 & -0.64 & 0.17 \\
\hline ice & Post-2000 DEM source date & -0.29 & 0.076 & 807 & -0.26 & 0.076 \\
\hline ice & Including ice border samples & -0.36 & 0.07 & 1541 & -0.33 & 0.07 \\
\hline ice & Including winters 2003-2008* & -0.43 & 0.066 & 2536 & -0.41 & 0.070 \\
\hline ice & Only winters 2003-2008* & -0.42 & 0.092 & 1303 & -0.41 & 0.097 \\
\hline ice & Samples on glaciers $>5 \mathrm{~km}^{2}$ & -0.28 & 0.089 & 621 & -0.26 & 0.091 \\
\hline ice & Samples on glaciers $<5 \mathrm{~km}^{2}$ & -0.53 & 0.11 & 484 & -0.43 & 0.11 \\
\hline ice & Myklebustbreen/Haugabreen (2003-2009) & +0.47 & 0.11 & 181 & +0.47 & 0.12 \\
\hline
\end{tabular}

impact on glacier trend estimates. This sensitivity is a direct result of interference of the non-uniform glacier behaviour within the study area with the (coarse) spatial pattern of these influencing parameters. In contrast, parameters that vary much more spatially such as elevation, slope, or aspect were found to be of less concern. Also smaller sample subsets are representative in that respect. Campaigns with low sample numbers and spatial clumping are most prone to biases. Owing to the rapidly decreasing laser power, campaigns towards the end of the acquisition period are most affected. However, severe cloud cover and subsequent exclusion of too many orbits can result in poor spatial distribution also for other campaigns. An example for this is the autumn 2005 campaign in southern Norway for which the only few ice samples mostly lie on old reference DEMs.
When relating ICESat trends to traditional glaciological measurements it is important to keep in mind that the subset of in situ monitored glaciers and the glaciers covered by our ICESat sample might not be fully comparable. Differences in estimated mass/volume changes are therefore likely to not (only) be caused by the methods used, but are rather a result of different sample composition. This is in line with the findings of e.g. Zemp et al. (2015) or Cogley (2009), who assign differences in mass budgets as from glaciological vs. geodetic measurements to sample composition rather than method-inherent causes. We find that with ICESat's random spatial sampling (with respect to glacier locations), we also capture many small ice bodies and snow patches. The share of samples, in terms of the area of the ice bodies on which single footprints lie, accurately reflects the size distribution of all glaciers and ice patches of the total glacierized surface 


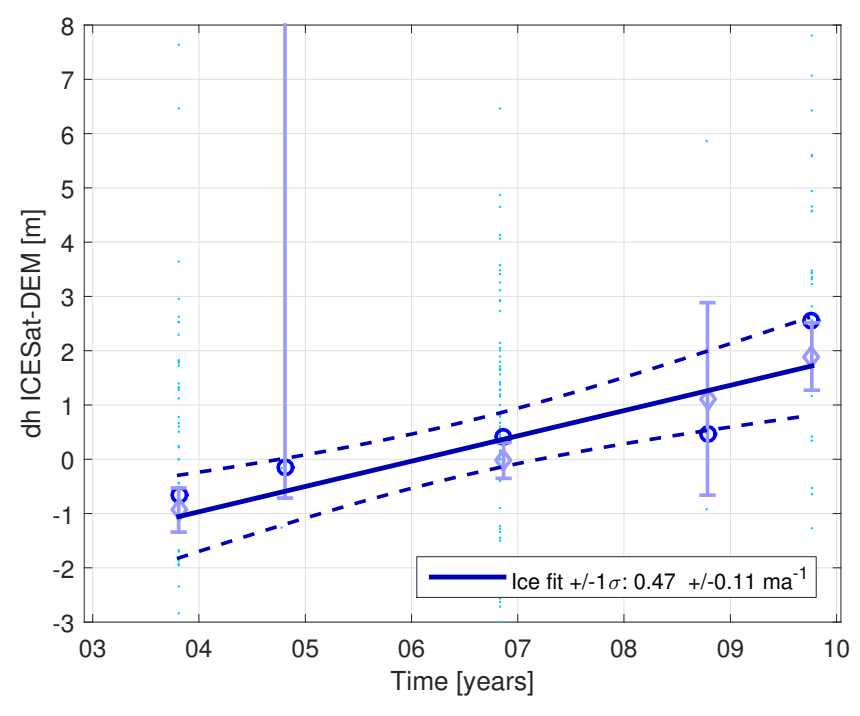

Figure 7. The autumn 2003-2009 trend for samples only on those glaciers that are covered by the autumn 2009 campaign (Myklebustbreen and Haugabreen) is strongly positive. The large error bars in 2004 and 2008 result from the very low campaign sample numbers of only three and seven samples respectively.

in southern Norway. While such small ice patches are commonly not monitored in situ, they are likely to be equally affected by climate change if not even more sensitive (Bahr and Radić, 2012; Fischer et al., 2014). Subsequent differences in glacier volume/mass changes as derived from ICESat, compared to traditional glaciological methods on selected valley glaciers, might therefore not agree if upscaled to the entire glacier population of a study area (Bahr and Radić, 2012).

The moderately negative glacier surface elevation change trends for the years 2003-2008 fit well with overall negative net cumulative mass balance series from glaciological measurements on glaciers in southern Norway. Trend slopes are robust against applied corrections or changes in sample composition as long as representativeness of the sample is guaranteed. Given the highly heterogeneous behaviour of Norwegian glaciers and the varying age of some parts of the reference DEM, both the measured dh (up to $20 \mathrm{~m}$ ) and the resulting trend confidence intervals are within an expected range. We find that smaller glaciers, and glaciers to the (dryer) east of the water divide, experienced stronger changes than larger and coastal glaciers. This is in agreement with the individual reactions of the monitored glaciers in southern Norway to the increasing atmospheric temperatures during the last decade.

To fill gaps from missing campaigns or to increase spatial resolution of estimated glacier trends, other authors have tried to obtain an alternative trend estimate fitted through winter ice samples (e.g. Gardner et al., 2013). However, our results for southern Norway show that ICESat is sensitive to - and even able to reproduce - yearly varying snow depths, and our glacier surface elevation change trends are more negative for winter ice samples. Even though the difference be- tween the winter and autumn trends is not significant in our study, the standard error of the winter trend is $50 \%$ larger which reflects the uncertainty added from yearly/spatially varying snow depths. Moreover, the different orbit pattern of the winter 2003 campaign (and first phase of autumn 2003 campaign) compared to all following campaigns may cause problems with representativeness and spatial distribution of the samples, especially if spatially varying elevation corrections such as our per-glacier correction $c_{\text {glac }}$ are applied. Our results therefore advise against including winter samples in glacier trend analyses. We also recommend including only footprints lying entirely on glaciers, i.e. excluding footprints that we classified as ice border samples. The signal from mixed ice/land footprints adds unnecessary uncertainty to the derived trends that does not justify the increased sample numbers.

Regarding the example of Myklebustbreen, we show that it may be possible to detect trends even for single glaciers. Unfortunately, no mass balance measurements exist to verify the positive surface elevation change found for this glacier. How confident we can be in such a local trend depends on appropriate temporal and spatial coverage. Our results show that the applicability of ICESat in arbitrary glacierized regions does not depend on a single factor only. Likewise, the minimum region size needed to derive valid estimates on glacier surface elevation change from ICESat cannot be expressed as a hard threshold but depends on a combination of factors specific to each area: glacier density and ICESat track density (i.e. sample size), representativeness of the ICESat sample, and homogeneity of the glacier signal within the study (sub-) region. In general, ICESat track density increases with latitude, making areas closer to the poles more favourable for ICESat studies. However, size and spatial distribution of glaciers as well as less cloud cover in dryer areas may result in large enough sample numbers even in small mountain regions at lower latitudes - as long as the representativeness condition is fulfilled. Representativeness of the sample may also be given for lower sample numbers than we found in southern Norway, where a glacier population is more homogeneous with respect to its topographic setting as well as mass balance changes/surface elevation trends. Spatially varying effects such as from DEM elevation bias or highly non-uniform glacier behaviour within the study area require larger sample numbers - and thus larger region sizes - to account for the introduced uncertainty. In that regard, southern Norway may not be an ideal location to test the limits of ICESat applicability, and in other mountain regions with more consistent reference DEMs even smaller study areas may potentially yield valid ICESat glacier surface elevation change estimates.

\subsection{Glacier trend sensitivity}

Given the temporal variability in annual surface mass balances from long-term in situ measurements, the glacier sur- 
face elevation change derived from ICESat data is not likely to represent a long-term trend. Our results are only representative for the development within the 5 years covered. It is in general not recommended to extrapolate trends derived from such a short time interval, neither for ICESat-derived trends, nor mass balance series in general.

Trend slopes are considerably less sensitive to missing/biasing campaigns in the middle of the ICESat acquisition period than to campaigns missing at either end. Inclusion of the non-representative 2009 campaign which diverges strongly from the assumed linear trend (corresponding to an assumed constant mass balance) significantly alters the trend slope. The considerable trend slope differences for our various sample subsets show that trends are even more sensitive to changes in sample composition or applied corrections when sample numbers are small.

For our data, we found that robust fitting methods, as used by e.g. Kääb et al. (2012) for ICESat glacier trends, result in comparable but somewhat steeper trend estimates as when fitting a $t$ distribution to the data. The error estimates of both methods overlap for all subsets/sets of corrections applied to the data set, thus the trends are not significantly different. A $t$ fit better captures the heavier tails of the sample distribution and includes the uncertainties in the data within the statistical model used to compute the fit. The iteratively lowered weighing of samples within the robust fitting technique (which assumes a normal distribution) results in a similar effect - although one can argue that the weights assigned to outliers are so small that data points that do not fit the trend essentially are removed, and thus sample numbers reduced. Consequently, according to Street et al. (1988), error estimates for the robust methods might not be correct. However, given that most outliers indeed correspond to erroneous measurement of either ICESat or reference elevations, exclusion of these samples from trend estimates might be desirable. We found that error estimates of both methods are very similar, and differences resulting from the different trend fitting approaches are of the same order as caused by changes to the sample composition or due to application of correction factors. We thus prefer to leave the question of whether robust or $t$ fits are more appropriate to derive elevation trends from ICESat open.

\subsection{The role of DEM quality and elevation errors}

Of all correction factors applied, the correction for constant offsets on glaciers introduced by DEM age $\left(c_{\text {glac }}\right)$ deserves special attention as it considerably increased the statistical significance of glacier surface elevation trends. Not only is the trend standard error halved, but the correction also makes the trend slope much more robust to changes in sample composition/elevation corrections. The correction thus captures and eliminates errors in the data set that have a far bigger effect on trends than, for example, different fitting techniques. By applying $c_{\text {glac }}$ we see an increase in trend slope even though the correction decreases ice $\mathrm{dh}$. The fact that single campaigns fit measured mass balance after application of the correction strongly indicates that this correction is important for accurately capturing glacier surface elevation development within the studied time period. The estimated glacier surface elevation trend of the sample, without accounting for DEM age offsets, is not significantly different from the former trend estimate, but the wider confidence interval, trend sensitivity, and large offsets of single campaigns are a clear sign that not all error sources were accounted for in the uncorrected data set. It also illustrates the importance of representativeness very well in terms of factors that may not be immediately obvious, such as spatially varying vertical offsets in the reference data. Note that a correction for "DEM age" as done here has a different significance for glaciers compared to stable ground. On glaciers that change their surface elevation over time, the spatially varying bias we see in our data set is likely to indeed be caused by different DEM ages. On top of that, other spatially varying biases due to mosaicking of data from different sources may add additional bias to glaciers. On land surfaces, the contrary is the case and the latter type of bias would usually play the main role while the age of the reference DEM is negligible except for areas and timescales where, e.g. vertical uplift due to postglacial rebound causes relevant age-dependent bias.

Where the correction is applied to spatial units with changing elevation - such as on glaciers - a certain consistency and repetition in spatial sampling is needed. The surface change signal contribution from a glacier sampled only by one overpass is removed by the $c_{\text {glac }}$ correction. While we found that the error from keeping the single overpass samples in our trend estimates is smaller than the uncertainty from not applying $c_{\text {glac }}$ we recommend removing these samples as the introduced bias corresponds to a systematic flattening of the trend. It should be kept in mind that for winter trends (summer trends on the southern hemisphere) this might affect most, if not all, of the March 2003 campaign samples due to the different ground track pattern of that campaign.

Correction of per-glacier offset is only possible in our study because the glaciers seem to mostly correspond to spatial units of consistent DEM age in Norway. The correction factor is independent of (not available) metadata for data quality and does not correspond to nor help to correct offsets of the surrounding terrain. In our case, zero-land trend, therefore, does not guarantee the absence of a time-dependent bias for glacier samples (with different distribution in terms of source date stamp). The assumption of a constant vertical offset per glacier is not necessarily valid everywhere, e.g. Swiss glaciers were not considered as unities in the mosaicking of airborne DEM acquisition flight lines but sometimes cut right across (M. Hölzle, personal communication, 2015). This resulted in differently timed outlines and elevation data for parts of the same glacier, further complicating DEM differencing with historic DEMs in the Alps, as done by Fischer et al. (2015). We faced similar challenges in our attempts 
to co-register ICESat and the reference DEMs. The spatial units (tiles or source time stamp of elevation contours) available to us did not correspond entirely with spatial units of data origin that would exhibit a constant spatial shift or elevation error. Other DEMs for larger areas, and especially national DEMs, are likely to contain similar inherent errors as we found for the Kartverket DEM, and Fischer et al. (2015) for historic Swiss DEMs, as they all consist of a patchwork of source data sets with various time stamps - especially in remote areas. Metadata on elevation data sources are rarely available, and DEMs might have been (post-) processed to optimize characteristics other than high elevation accuracy, for instance smoothness or realistic visual appearance.

Global DEMs, such as the ASTER GDEMs or the upcoming TanDEM-X DEM, might also be a composite of numerous units of unknown or different age or elevation biases. While the radar-based elevations from the SRTM were acquired within a short time frame which eliminates DEM age error, the DEM still remains a patchwork from acquisitions from different overpasses, and elevation differences to ICESat elevations were found to vary spatially (e.g. Carabajal and Harding, 2006). Van Niel et al. (2008) found that shifts of subpixel magnitude result in artificially generated elevation differences of the same magnitude as the actual, measured elevation differences between the SRTM and national higherresolution DEMs for two mountainous test sites in Australia and China. As an additional source of uncertainty for radarbased DEMs when serving as reference elevation, radar penetration into snow and ice is estimated to be in the range of several metres (Gardelle et al., 2012; Kääb et al., 2015) and can be considered to be another type of spatial pattern to which our per-glacier correction could be of benefit. However, further analyses on this end would be necessary, given the strong gradients and differences in snow/ice consistency between accumulation and ablation zones of a glacier that make radar penetration vary strongly even within a single glacier (Dall et al., 2001; Müller, 2011; Rignot et al., 2001).

ICESat GLAS data come with numerous correction terms which might signal uncertainty in the elevation values. For saturation correction, which is in the order of decimetres, we showed that the effect is negligible over rough mountain terrain and does not affect our results. Moreover, the saturation flag does not necessarily correspond with lower quality data over mountainous terrain, neither on ice nor land surfaces. The correction might not capture the effect of waveform saturation over such terrain appropriately. It is not generally recommended for land surfaces (NSIDC, 2012), and the error potentially resulting from waveform saturation is in the order of decimetres only. However, Molijn et al. (2011) found a larger occurrence of saturated samples at the transition from (rough) glacier-free terrain to (flat) glacier surfaces in the Dry Valleys in Antarctica. This can be explained with the adaptive gain setting of ICESat's GLAS instrument: the gain of the sensor is dynamically adjusted based on the recorded signal (NSIDC, 2012) and might not adapt fast enough for an abrupt change in the recorded waveform shapes between a footprint on dark, rough rocks and a flat, bright ice surface. A preferred occurrence of saturated samples and subsequent elevation error at glacier margins, where surface elevation changes are likely more pronounced, could potentially lead to a systematic bias in ICESat-derived glacier surface elevation change trends. In our study area we could not detect a systematic pattern in the spatial distribution of the saturated samples or where ICESat passes over glacier margins and experiences a land/ice surface type change. We believe that this is due to the small size of mountain glaciers and the rough surface topography both on land and glaciers (compared to large Antarctic outlet glaciers) that never really allowed the sensor to settle for a certain gain. Nevertheless, from the findings of Molijn et al. (2011) we cannot exclude that there is potential for a systematic bias from waveform saturation at ice/land transitions in other areas, and we recommend considering this possibility when applying our method in an arbitrary glacier region.

Likewise, other available corrections and biases of even smaller magnitude, such as intercampaign bias $(<8 \mathrm{~cm}$, Hofton et al., 2013), the optional range increment for land samples (d_ldRngOff), and the GmC correction introduced in GLAS data of release 34 are of negligible importance compared to corrections applied to the reference DEM elevations. However, it cannot be excluded that these corrections might become relevant if a reference DEM without vertical bias were available, which would eliminate the current main error source.

On stable ground, the problem of time-dependent elevation differences due to surface elevation change is not present, but the artificial dh resulting from subpixel shifts or elevation-dependent errors were still found to compete with real, measured differences between the DEMs. This mainly has implications on the size of spatial and temporal units needed to aggregate footprints to get meaningful results. The example of Hardangervidda illustrates the potential of results on a local scale for areas with good quality reference elevations. Thereby, spatial resolution of the reference DEM is of less importance than the absence of (spatially varying) shifts or other biases in the data, resulting in narrower dh distributions of the low-resolution SRTM DEM compared to the Kartverket DEM, which seems to be of poorer quality in this area. However, the DEM resolution has to be small enough to appropriately capture the local relief variations. In more rugged terrain with large elevation variation within a single footprint, the spatial resolution of the DEM would likely play a more important role than on rather flat areas like Hardangervidda. We found the reference DEM rather than ICESat to limit more localized results that would reflect spatial variation or patterns of glacier change within the study area.

For glacier trend applications, the time to collect better reference DEMs for improved retrospect ICESat analyses has likely passed where glaciers experienced large changes in volume over the past decade. Still, the biases in the old ref- 
erence DEMs of our study, originating from 10 to 20 years prior to the ICESat acquisition period, obviously became detectable and quantifiable. This fact underlines that ICESat data fully bear the potential to serve as a sample of glacier surface elevations in the 2000s even for areas where we currently do not yet have very accurate reference DEMs.

\section{Conclusion}

For the example of southern Norway, we show that ICESat elevations normalized to a reference DEM are fully capable of providing robust and realistic glacier surface elevation trends for the years 2003-2008 in mountainous terrain with scattered small- and medium-size glaciers. We estimate an average ice surface elevation change of $-0.39 \pm 0.07 \mathrm{~m}$ (robust fit) and $-0.33 \pm 0.07 \mathrm{~m}$ ( $t$ fit) ice per year in 2003-2008 for southern Norwegian glaciers. Our estimate corresponds very well to the area-weighted average of observed cumulative mass balances from in situ and geodetic mass balance measurements on eight glaciers in the study area.

Despite sparse glacier cover of the study area, the coarse spatial sample of ICESat represents southern Norwegian glaciers accurately in terms of elevation, slope, aspect, spatial location, and area of the glaciers. Representativeness of the sample is also given for individual campaigns, and is a prerequisite for robust trend results. Non-representative campaigns have the potential to alter trends. Especially in terms of glacier area, ICESat samples reflect the size distribution of all glaciers in southern Norway considerably better than the (predominantly large) glaciers included in the in situ mass balance network in Norway.

The number of ICESat footprints on glaciers (1233 after filtering) within the study area was found to be large enough to allow for spatial and thematic subsampling. The considerable differences between trends from different sample subsets reflect the wide range of observed cumulative mass balances in the study area. Reasonably, we see a more negative elevation trend of continental and small glaciers compared to coastal or large glaciers respectively. Our glacier elevation change trends thus capture very varied glacier behaviour within the study area, and also depict glaciers with positive mass balance, as seen for Myklebustbreen and Hansebreen. On this example, we show that it may be possible to detect trends even for single well-covered glaciers, but with increased uncertainty due to spatially clumped sampling and missing data for some campaigns.

The applicability of ICESat in arbitrary glacierized regions depends on a combination of factors rather than a minimum region or sample size. The number of samples is determined by glacier density in relation to ICESat track density and the topography/climate-determined fraction of valid elevation measurements in the study region. Their representativeness, however, depends on the homogeneity of both the glacier topographic setting and their mass balance sig- nal within the study area, as well as other spatially varying effects such as from DEM elevation bias. These factors are inherent for each region (and reference DEM) and will affect the sample/area size needed for a valid surface elevation change estimate. Uncertainties in reference DEM elevations exceed ICESat uncertainties by a magnitude. Elevation bias of unknown spatial units of the three assessed reference DEMs add noise that match or exceed measured elevation differences. These biases result from subpixel horizontal and vertical shifts, elevation-dependent bias, and varying source time stamps of the reference DEM of up to 20 years prior to ICESat acquisition. If not accounted for, spatially varying biases in combination with varying sample distribution over time may not cancel out and can affect the results by causing false trends. Representativeness of the sample in terms of such spatially varying bias in the reference DEM was found to be more important (and less given) than for terrain parameters like elevation or aspect. Due to their coarse spatial pattern, the DEM errors add varying but systematic bias in contrast to the random effects from geographic ICESat footprint distribution.

We developed a new per-glacier correction to harmonize the effect of age-dependent offsets between ICESat and the patchy reference DEM of unknown, but spatially varying source date. This correction greatly increased the statistical significance and robustness of our glacier change trend, and single campaigns also fit measured mass balance after application of the correction. For national or global DEMs in other regions, we see large potential from this correction or modified versions of it, for reducing glacier trend uncertainty related to spatio-temporal biases, such as from imperfect mosaicking, orbit inaccuracies, or radar penetration.

Our study shows that ICESat analyses in mountain terrain are currently limited by the reference DEMs rather than ICESat performance. ICESat provides an accurate sample of global glacier surface elevations in the 2000s. There is still large potential, even several years after the mission ended, for new upcoming DEMs to improve ICESat analysis in retrospect (e.g. TanDEM-X, new mapping agency DEMs). After its launch, ICESat2, with its denser cross- and alongtrack sampling and improved performance over rough surfaces (Kramer, 2015), will have the capability to provide an even more detailed, accurate, and valuable sample of glacier surface elevations using the methods outlined here.

\section{Data availability}

All data sources are given in Sect. 2.

The Supplement related to this article is available online at doi:10.5194/tc-10-2129-2016-supplement. 
Author contributions. Désirée Treichler designed the study, performed data analyses, and prepared the manuscript. Andreas Kääb designed the study and edited the manuscript.

Acknowledgements. The study was funded by the European Research Council under the European Union's Seventh Framework Programme (FP/2007-2013)/ERC grant agreement no. 320816, the ESA project Glaciers_cci (4000109873/14/I-NB) and the Department of Geosciences, University of Oslo. We are very grateful to NASA and USGS for free provision of the ICESat data and the SRTM DEM respectively, to the Norwegian mapping agency for their topographic DEMs, and to the Norwegian Water Resources and Energy Directorate for glacier outlines, mass balance data, and the Hardangervidda lidar DEM.

Edited by: G. H. Gudmundsson

Reviewed by: R. C. Lindenbergh and one anonymous referee

\section{References}

Andreassen, L. M. and Winsvold, S. H. (Eds.): Inventory of Norwegian glaciers, NVE Rapport 38, Norges Vassdrags- og energidirektorat, 236 pp., 2012.

Andreassen, L. M., Elvehøy, H., Kjøllmoen, B., Engeset, R. V., and Haakensen, N.: Glacier mass-balance and length variation in Norway, Ann. Glaciol., 42, 317-325, doi:10.3189/172756405781812826, 2005.

Andreassen, L. M., Elvehøy, H., Kjøllmoen, B., and Engeset, R. V.: Reanalysis of long-term series of glaciological and geodetic mass balance for 10 Norwegian glaciers, The Cryosphere, 10, 535552, doi:10.5194/tc-10-535-2016, 2016.

Bahr, D. B. and Radić, V.: Significant contribution to total mass from very small glaciers, The Cryosphere, 6, 763-770, doi:10.5194/tc-6-763-2012, 2012.

Bliss, A., Hock, R., and Radić, V.: Global response of glacier runoff to twenty-first century climate change, J. Geophys. Res.-Earth, 119, 717-730, doi:10.1002/2013jf002931, 2014.

Bolch, T., Sørensen, L. S., Simonsen, S. B., Mölg, N., Machguth, H., Rastner, P., and Paul, F.: Mass loss of Greenland's glaciers and ice caps 2003-2008 revealed from ICESat laser altimetry data, Geophys. Res. Lett., 40, 875-881, doi:10.1002/grl.50270, 2013.

Carabajal, C. C. and Harding, D. J.: SRTM C-Band and ICESat Laser Altimetry Elevation Comparisons as a Function of Tree Cover and Relief, Photogr. Sci. Eng., 72, 287-298, 2006.

Cogley, J. G.: Geodetic and direct mass-balance measurements: comparison and joint analysis, Ann. Glaciol., 50, 96-100, 2009.

Dall, J., Madsen, S. N., Keller, K., and Forsberg, R.: Topography and penetration of the Greenland Ice Sheet measured with Airborne SAR Interferometry, Geophys. Res. Lett., 28, 1703-1706, doi:10.1029/2000g1011787, 2001.

Farr, T. G. and Kobrick, M.: Shuttle radar topography mission produces a wealth of data, Eos T. A. Geophys. Un., 81, 583-585, doi:10.1029/EO081i048p00583, 2000.
Farr, T. G., Rosen, P. A., Caro, E., Crippen, R., Duren, R., Hensley, S., Kobrick, M., Paller, M., Rodriguez, E., Roth, L., Seal, D., Shaffer, S., Shimada, J., Umland, J., Werner, M., Oskin, M., Burbank, D., and Alsdorf, D.: The Shuttle Radar Topography Mission, Rev. Geophys., 45, RG2004, doi:10.1029/2005rg000183, 2007.

Fischer, M., Huss, M., Barboux, C., and Hoelzle, M.: The new Swiss Glacier Inventory SGI2010: relevance of using highresolution source data in areas dominated by very small glaciers, Arct. Antarct. Alp. Res., 46, 933-945, doi:10.1657/1938-424646.4.933, 2014.

Fischer, M., Huss, M., and Hoelzle, M.: Surface elevation and mass changes of all Swiss glaciers 1980-2010, The Cryosphere, 9, 525-540, doi:10.5194/tc-9-525-2015, 2015.

Gardelle, J., Berthier, E., and Arnaud, Y.: Impact of resolution and radar penetration on glacier elevation changes computed from DEM differencing, J. Glaciol., 58, 419-422, doi:10.3189/2012JoG11J175, 2012.

Gardner, A. S., Moholdt, G., Cogley, J. G., Wouters, B., Arendt, A. A., Wahr, J., Berthier, E., Hock, R., Pfeffer, W. T., Kaser, G., Ligtenberg, S. R. M., Bolch, T., Sharp, M. J., Hagen, J. O., van den Broeke, M. R., and Paul, F.: A Reconciled Estimate of Glacier Contributions to Sea Level Rise: 2003 to 2009, Science, 340, 852-857, doi:10.1126/science.1234532, 2013.

GLIMS and NSIDC: GLIMS Glacier Database, Version 1, NSIDC: National Snow and Ice Data Center, Boulder, Colorado USA, doi:10.7265/N5V98602, 2005, updated 2012.

Hofton, M. A., Luthcke, S. B., and Blair, J. B.: Estimation of ICESat intercampaign elevation biases from comparison of lidar data in East Antarctica, Geophys. Res. Lett., 40, 5698-5703, doi:10.1002/2013g1057652, 2013.

Howat, I. M., Smith, B. E., Joughin, I., and Scambos, T. A.: Rates of southeast Greenland ice volume loss from combined ICESat and ASTER observations, Geophys. Res. Lett., 35, L17505, doi:10.1029/2008g1034496, 2008.

Huss, M.: Density assumptions for converting geodetic glacier volume change to mass change, The Cryosphere, 7, 877-887, doi:10.5194/tc-7-877-2013, 2013.

Immerzeel, W. W., van Beek, L. P. H., and Bierkens, M. F. P.: Climate Change Will Affect the Asian Water Towers, Science, 328, 1382-1385, doi:10.1126/science.1183188, 2010.

Jacob, T., Wahr, J., Pfeffer, W. T., and Swenson, S.: Recent contributions of glaciers and ice caps to sea level rise, Nature, 482, 514-518, doi:10.1038/nature10847, 2012.

Jansson, P., Hock, R., and Schneider, T.: The concept of glacier storage: a review, J. Hydrol., 282, 116-129, doi:10.1016/S00221694(03)00258-0, 2003.

Kääb, A., Berthier, E., Nuth, C., Gardelle, J., and Arnaud, Y.: Contrasting patterns of early twenty-first-century glacier mass change in the Himalayas, Nature, 488, 495-498, doi:10.1038/nature11324, 2012.

Kääb, A., Treichler, D., Nuth, C., and Berthier, E.: Brief Communication: Contending estimates of 2003-2008 glacier mass balance over the Pamir-Karakoram-Himalaya, The Cryosphere, 9, 557564, doi:10.5194/tc-9-557-2015, 2015.

Kartverket: Terrengmodeller - land, Kartverket; available at: http://www.kartverket.no/Kart/Kartdata/Terrengmodeller/ Terrengmodell-10-meters-grid/, last accessed: 6 June 2016. 
Ke, L., Ding, X., and Song, C.: Heterogeneous changes of glaciers over the western Kunlun Mountains based on ICESat and Landsat-8 derived glacier inventory, Remote Sens. Environ., 168, 13-23, doi:10.1016/j.rse.2015.06.019, 2015.

Kjøllmoen, B., Andreassen, L. M., Engeset, R. V., Elvehøy, H., Jackson, M., and Giesen, R. H.: Glaciological investigations in Norway in 2005, edited by: Kjøllmoen, B., Norwegian Water Resources and Energy Directorate (NVE), Oslo, Norway, NVE Report 2 2006, 99 pp., 2006.

Kjøllmoen, B., Andreassen, L. M., Elvehøy, H., Jackson, M., Giesen, R. H., and Tvede, A. M.: Glaciological investigations in Norway in 2008, edited by: Kjøllmoen, B., Norwegian Water Resources and Energy Directorate (NVE), Oslo, Norway, NVE Report 2 2009, 80 pp., 2009.

Kjøllmoen, B., Andreassen, L. M., Elvehøy, H., Jackson, M., and Giesen, R. H.: Glaciological investigations in Norway in 2009, edited by: Kjøllmoen, B., Norwegian Water Resources and Energy Directorate (NVE), Oslo, Norway, NVE Report 2, 85 pp. + app., 2010.

Kjøllmoen, B., Andreassen, L. M., Elvehøy, H., Jackson, M., and Giesen, R. H.: Glaciological investigations in Norway in 2010, edited by: Kjøllmoen, B., Norwegian Water Resources and Energy Directorate (NVE), Oslo, Norway, NVE Report 3, 89 pp. + app., 2011.

Kramer, H. J.: ICESat-2 (Ice, Cloud and land Elevation Satellite2), available at: https://directory.eoportal.org/web/eoportal/ satellite-missions/i/icesat-2, last access: 20 November 2015.

Kropáček, J., Neckel, N., and Bauder, A.: Estimation of Mass Balance of the Grosser Aletschgletscher, Swiss Alps, from ICESat Laser Altimetry Data and Digital Elevation Models, Remote Sens., 6, 5614, doi:10.3390/rs6065614, 2014.

Lange, K. L., Little, R. J. A., and Taylor, J. M. G.: Robust Statistical Modeling Using the T-Distribution, J. Am. Stat. Assoc., 84, 881896, doi:10.2307/2290063, 1989.

Marzeion, B., Jarosch, A. H., and Hofer, M.: Past and future sealevel change from the surface mass balance of glaciers, The Cryosphere, 6, 1295-1322, doi:10.5194/tc-6-1295-2012, 2012.

Melvold, K. and Skaugen, T.: Multiscale spatial variability of lidar-derived and modeled snow depth on Hardangervidda, Norway, Ann. Glaciol., 54, 273-281, doi:10.3189/2013AoG62A161, 2013.

Moholdt, G., Nuth, C., Hagen, J. O., and Kohler, J.: Recent elevation changes of Svalbard glaciers derived from ICESat laser altimetry, Remote Sens. Environ., 114, 2756-2767, doi:10.1016/j.rse.2010.06.008, 2010.

Molijn, R. A., Lindenbergh, R. C., and Gunter, B. C.: ICESat laser full waveform analysis for the classification of land cover types over the cryosphere, Int. J. Remote Sens., 32, 8799-8822, doi:10.1080/01431161.2010.547532, 2011.

Müller, K.: Microwave penetration in polar snow and ice: Implications for GPR and SAR, PhD thesis, Department of Geosciences, University of Oslo, Norway, 2011.

NASA JPL: NASA Shuttle Radar Topography Mission Global 30 arc second, NASA LP DAAC, doi:10.5067/MEaSUREs/SRTM/SRTMGL30.002, 2013.

Neckel, N., Kropáček, J., Bolch, T., and Hochschild, V.: Glacier mass changes on the Tibetan Plateau 2003-2009 derived from ICESat laser altimetry measurements, Environ. Res. Lett., 9, 014009, doi:10.1088/1748-9326/9/1/014009, 2014.
Nesje, A., Bakke, J., Dahl, S. O., Lie, Ø., and Matthews, J. A.: Norwegian mountain glaciers in the past, present and future, Global Planet. Change, 60, 10-27, doi:10.1016/j.gloplacha.2006.08.004, 2008.

Nilsson, J., Sandberg Sørensen, L., Barletta, V. R., and Forsberg, R.: Mass changes in Arctic ice caps and glaciers: implications of regionalizing elevation changes, The Cryosphere, 9, 139-150, doi:10.5194/tc-9-139-2015, 2015.

NSIDC: GLAS Altimetry HDF5 Product Usage Guide, NASA DAAC at the National Snow and Ice Data Center, Boulder, Colorado USA, 2012.

NSIDC: GLAS/ICESat L1 and L2 Global Altimetry Data, Version 34, NASA DAAC at the National Snow and Ice Data Center, Boulder, Colorado USA, available at: http://nsidc.org/data/docs/ daac/glas_icesat_11_12_global_altimetry.gd.html, 2014.

NVE: Glacier outlines, Norges Vassdrags- og energidirektorat, digital data available at: https://www.nve.no/hydrology/glaciers/ glacier-data, last access: 28 August 2016.

Nuth, C. and Kääb, A.: Co-registration and bias corrections of satellite elevation data sets for quantifying glacier thickness change, The Cryosphere, 5, 271-290, doi:10.5194/tc-5-271-2011, 2011.

Nuth, C., Moholdt, G., Kohler, J., Hagen, J. O., and Kääb, A.: Svalbard glacier elevation changes and contribution to sea level rise, J. Geophys. Res., 115, doi:10.1029/2008jf001223, 2010.

NVE: Climate indicator products, Norwegian Water Resources and Energy Directorate, online glacier database, available at: http:// glacier.nve.no/viewer/CI/ (last access: 31 May 2016), 2016.

Rabus, B., Eineder, M., Roth, A., and Bamler, R.: The shuttle radar topography mission - a new class of digital elevation models acquired by spaceborne radar, ISPRS J. Photogramm., 57, 241262, doi:10.1016/S0924-2716(02)00124-7, 2003.

Radić, V. and Hock, R.: Regionally differentiated contribution of mountain glaciers and ice caps to future sea-level rise, Nat. Geosci., 4, 91-94, doi:10.1038/Ngeo1052, 2011.

Radić, V., Bliss, A., Beedlow, A. C., Hock, R., Miles, E., and Cogley, J. G.: Regional and global projections of twenty-first century glacier mass changes in response to climate scenarios from global climate models, Clim. Dynam., 42, 37-58, doi:10.1007/s00382-013-1719-7, 2014.

Rignot, E., Echelmeyer, K., and Krabill, W.: Penetration depth of interferometric synthetic-aperture radar signals in snow and ice, Geophys. Res. Lett., 28, 3501-3504, doi:10.1029/2000g1012484, 2001.

Schutz, B. E., Zwally, H. J., Shuman, C. A., Hancock, D., and DiMarzio, J. P.: Overview of the ICESat Mission, Geophys. Res. Lett., 32, L21S01, doi:10.1029/2005g1024009, 2005.

Slobbe, D. C., Lindenbergh, R. C., and Ditmar, P.: Estimation of volume change rates of Greenland's ice sheet from ICESat data using overlapping footprints, Remote Sens. Environ., 112, 42044213, doi:10.1016/j.rse.2008.07.004, 2008.

Street, J. O., Carroll, R. J., and Ruppert, D.: A Note on Computing Robust Regression Estimates via Iteratively Reweighted Least Squares, Am. Stat., 42, 152-154, doi:10.2307/2684491, 1988.

Van Niel, T. G., McVicar, T. R., Li, L., Gallant, J. C., and Yang, Q.: The impact of misregistration on SRTM and DEM image differences, Remote Sens. Environ., 112, 2430-2442, doi:10.1016/j.rse.2007.11.003, 2008. 
Viviroli, D., Dürr, H. H., Messerli, B., Meybeck, M., and Weingartner, R.: Mountains of the world, water towers for humanity: Typology, mapping, and global significance, Water Resour. Res., 43, W07447, doi:10.1029/2006wr005653, 2007.

Winsvold, S. H., Andreassen, L. M., and Kienholz, C.: Glacier area and length changes in Norway from repeat inventories, The Cryosphere, 8, 1885-1903, doi:10.5194/tc-8-1885-2014, 2014.

Zemp, M., Frey, H., Gärtner-Roer, I., Nussbaumer, S. U., Hoelzle, M., Paul, F., Haeberli, W., Denzinger, F., Ahlstrøm, A. P., Anderson, B., and others: Historically unprecedented global glacier decline in the early 21 st century, J. Glaciol., 61, 745-762, doi:10.3189/2015JoG15J017, 2015.
Zwally, H. J., Schutz, R., Bentley, C., Bufton, J., Herring, T., Minster, J., Spinhirne, J., and Thomas, R.: GLAS/ICESat L2 Global Land Surface Altimetry Data (HDF5), Version 33, GLAH14, NASA DAAC at the National Snow and Ice Data Center, Boulder, Colorado USA, doi:10.5067/ICESAT/GLAS/DATA207, 2012. 